\title{
HUBUNGAN IKLIM KERJA DENGAN KINERJA PERAWAT DI RUMAH SAKIT IBNU SINA MAKASSAR
}

\author{
Suriyani $^{1 *}$, Evi Lusiana ${ }^{2}$, Sri Hastuti Mulyani ${ }^{3}$ \\ 1.2.3 Stikes Panakkukang Makassar, Makassar \\ Suriyani : Program Studi Profesi Ners, Stikes Panakkukang Makassar, Jln. Adyaksa No 5 Makassar \\ Kota Makassar, Sulawesi Selatan - 90231, E-Mail : anhyatala@gmail.com
}

\begin{abstract}
Abstrak
Kinerja perawat merupakan gambaran pencapaian pelaksanaan kegiatan dalam melakukan pendokumentasian. Salah satu faktor yang mendukung kinerja yang baik yakni iklim kerja. Iklim kerja merupakan persepsi tentang suasana lingkungan kerja yang dirasakan oleh seorang perawat dalam organisasi. Jika iklim kerja dipersepsikan positif maka akan meningkatkan kinerja perawat dalam hal memberikan pelayanan yang bermutu. Tujuan penelitian ini bertujuan untuk mengetahui hubungan antara iklim kerja dengan kinerja perawat di RS Ibnu Sina Makassar. Desain yang digunakan dalam penelitian ini adalah deskriptif analitik dengan pendekatan cross sectional study dengan jumlah sampel 60 responden. Hasil penelitian diperoleh iklim kerja dalam kategori baik sebanyak 47 responden $(78,3 \%)$ dan iklim kerja dalam kategori kurang baik sebanyak 13 responden $(21,7 \%)$ dengan kinerja kategori baik sebanyak 53 orang $(88,3 \%)$ dan dalam kategori kurang baik sebanyak 7 orang $(11,7 \%)$. Analisa bivariate diperoleh nilai $\mathrm{p}=0,004$ yang berarti terdapat hubungan iklim kerja dengan kinerja perawat pelaksana di RS Ibnu Sina Makassar. Untuk itu sebaiknya rumah sakit meningkatkan kualitas dan kuantitas khususnya dalam lingkungan kerja sehingga perawat pelaksana mampu melaksanakan pendokumentasian yang lebih optimal.
\end{abstract}

\section{Kata kunci : Iklim Kerja, Kinerja Perawat}

\section{Abstract}

Nurse performance is a description of the implementation of activities in documenting. One of the factors that support good performance is the work climate. Work climate is the perception of the work atmosphere felt by a nurse in the organization. If the work climate is perceived positively, it will improve the performance of nurses in providing quality services. The aims of this study was to see the relation between work climate and nurse performance at Ibnu Sina Hospital Makassar. The design used was descriptive analytic with a cross sectional study approach with a sample size of 60 respondents. The results showed that the work climate in the good category were 47 respondents (78.3\%) and the work climate in the unfavorable category were 13 respondents (21.7\%), There were 53 respondents (88.3\%) in good category of performance, and in the poor category were 7 respondents $(11.7 \%)$. Bivariate analysis obtained p value $=0.004$, which means that there is a relation between work climate and the performance of nurses at Ibnu Sina Hospital Makassar. For this reason, the hospital should improve the quality and quantity in the work environment so that the nurse administrators are able to carry out more optimal documentation.

Keywords: Work Climate, Nurse Performance 


\section{PENDAHULUAN}

Kinerja perawat dalam suatu rumah sakit merupakan suatu modal penting bagi rumah sakit untuk mencapai tujuan (Sari dan Puspita, 2017). Kinerja perawat dalam memberikan layanan kesehatan juga merupakan factor yang sangat berpengaruh dalam pecapaian mutu pelayanan keparawatan yang dimana ditentukan oleh 3 hal yaitu kemampuan, keinginan dan lingkungan kerja (Hamongan dan Damanik, 2019).

Rumah sakit yang merupakan organisasi dalam menyediakan pelayanan kesehatan ini berbeda dengan karalteristik organisasi lain. Yang dimana menyebabkan iklim kerjanya pun berbeda dengan yang lainnya, utamanya pada perawat yang merupakan tenaga kerja yang mayoritas di sebuah rumah sakit (Minaria, 2019)

Menurut Brown dan Leigh dalam Sari dan Puspita (2017) Iklim kerja berperan penting dalam suatu organisasi untuk menciptakan lingkungan dimana orangorang didalamnya merasa nyaman dalam mencapai potensi yang merupakan kunci dari keunggulan terhadap persaingan. Menciptakan iklim kerja yang baik dalam rumah sakit seperti memperhatikan suasana kerja akan memberikan motivasi kerja yang tinggi dan semangat kerja pada seorang perawat.

Hasil penelitian yang dilakukan kepada perawat di Namibia didapatkan faktor-faktor yang mempengaruhi kinerja perawat diidentifikasi seperti: kurangnya pengakuan kepada karyawan yang berkinerja baik, tidak adanya sistem penilaian kinerja formal dan iklim kerja yang buruk (Awases dan Roos 2015). Penelitian Asi (2011)'mendapatkan bahwa kinerja juga berpengaruh cukup kuat terhadap iklim kerja. Semakin baik iklim kerja maka kinerja yang dihasilkan akan baik.

Rumah Sakit Ibnu Sina Makassar merupakan rumah sakit swasta tipe A dengan jumlah tenaga perawat pelaksana sebanyak 71 orang. Tujuan dari rumah sakit tersebut untuk memberikan pelayanan yang bermutu sesuai dengan visi misi rumah sakit, yang semakin baik, terpercaya dan berorientasi pada kepuasan pelanggan. Hasil pengamatan dan wawancara dengan 5 orang perawat pelaksana di ruangan mengatakan dalam rumah sakit ini masih kurang dalam mengontrol dan mengabaikan tentang iklim kerja terutama dalam pemberian sanksi kepada perawat yang sering telat, reward kepada perawat yang berprestasi, pengakuan, bahkan terkadang ada perawat yang kurang mendapatkan dukungan atau motivasi sesama tim. Perawat dalam bekerja mampu melakukan peran sesuai dengan tugas dan tanggungjawab yang telah diberikan. Masalah yang ditemukan adanya keluhan perawat terhadap beban kerjanya salah 
satunya mengurus administrasi dan sebagian perawat ada yang merasa tuntunan kerja tidak sebanding dengan kompensasi yang didapatkan.

\section{METODE PENELITIAN}

Jenis penelitian yang digunakan adalah deskriptif analitik dengan pendekatan cross sectional study yang dimana dilakukan pengukuran/observasi satu kali pada satu waktu untuk melihat hubungan antara variable dengan melakukan pengukuran sesaat dengan menganalisis hubungan iklim kerja dengan kinerja perawat di RS Ibnu Sina Makassar (Nursalam (2017).

Populasi dalam penelitian ini adalah sebanyak 71 orang perawat pelaksana. Terdiri dari 6 ruangan yaitu R.R Isolasi $=4$ responden, R.R Bukhori $=9$ responden, R.R Assafii $=12$ responden, $\mathrm{R} . \mathrm{R}$ Assifaa $=$ 12 responden, R.R Ar Rahman $=11$ responden, dan R.R As Salam $=13$ responden. Teknik pengambilan sampel dengan menggunakan Proportional stratified random sampling yang merupakan strata atau kedudukan subjek (seseorang) di masyarakat.

Alat pengumpulan data menggunakan kuesioner penelitian yang dimana kuisioner iklim kerja dengan skala likert sedangkan untuk kinerja perawat meggunakan skala gutman. Prosedur pengumpulan data dalam bentuk data primer dan sekunder dengan teknik analisa data secara univariat dan bivariate. Serta telah dilakukan uji etik dengan No: 0010/KEPK-PTKMKS/I/2020.

Uji statistik dalam penelitian ini adalah Uji Chi Square, dengan nilai $(\alpha=0.05)$.

\section{HASIL DAN PEMBAHASAN}

Hasil penelitian di RS Ibnu Sina Makassar dideskripsikan sebagai berikut :

Tabel 1 Distribusi Responden Berdasarkan Iklim Kerja Di RS Ibnu Sina Makassar Tahun 2020.

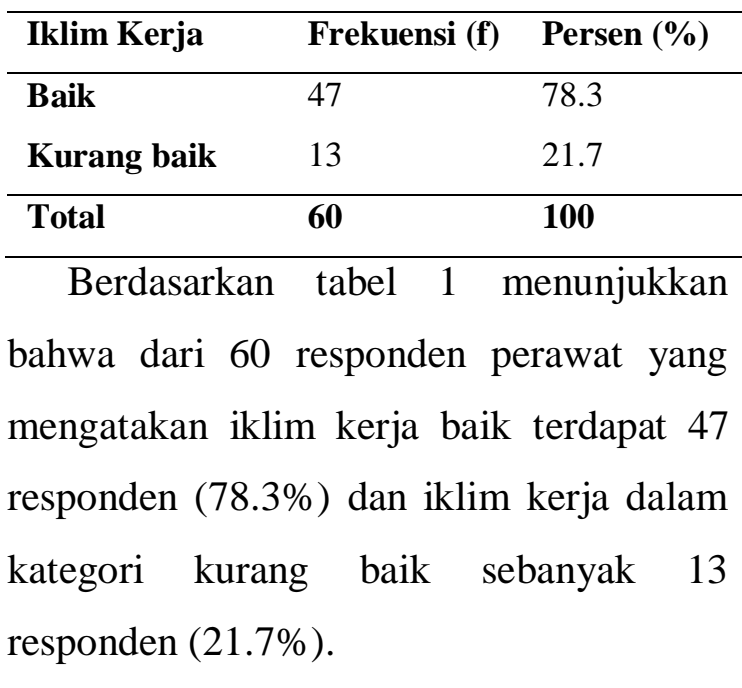

Tabel 2 Distribusi Responden Berdasarkan Kinerja Perawat Di RS Ibnu Sina Makassar Tahun 2020.

\begin{tabular}{lcc}
\hline Kinerja & \multicolumn{1}{c}{ Frekuensi (f) } & Persen (\%) \\
\hline Baik & 53 & 88.3 \\
Kurang baik & 7 & 11.7 \\
\hline Total & $\mathbf{6 0}$ & $\mathbf{1 0 0}$ \\
\hline \multicolumn{1}{c}{ Berdasarkan } & tabel & menunjukkan \\
bahwa dari & 60 & responden yang memiliki \\
kinerja dalam & kategori baik & sebanyak 53 \\
responden (88.3\%), dan yang memiliki \\
kinerja yang kurang baik & sebanyak 7 \\
responden (11.7\%).
\end{tabular}


Tabel 3 Hubungan Iklim Kerja dengan

Kinerja Perawat di RS Ibnu Sina Makassar 2020

\begin{tabular}{|c|c|c|c|c|c|c|c|}
\hline & \multicolumn{4}{|c|}{ Kinerja Perawat } & & & \\
\hline \multirow{3}{*}{$\begin{array}{l}\text { Iklim } \\
\text { Kerja }\end{array}$} & \multirow{2}{*}{\multicolumn{2}{|c|}{ Baik }} & \multirow{2}{*}{\multicolumn{2}{|c|}{$\begin{array}{c}\text { Kurang } \\
\text { baik }\end{array}$}} & \multirow{2}{*}{\multicolumn{2}{|c|}{ Total $(\%)$}} & \multirow[t]{3}{*}{$p$} \\
\hline & & & & & & & \\
\hline & (n) & $(\%)$ & (n) & $(\%)$ & (n) & $(\%)$ & \\
\hline Baik & 45 & 75.0 & 2 & 3.3 & 47 & 100 & \\
\hline Kurang & 8 & 13.3 & 5 & 8.3 & 13 & 100 & $* 0$ \\
\hline baik & & & & & & & 004 \\
\hline Total & 53 & 88.3 & 7 & 11.7 & 60 & 100 & \\
\hline
\end{tabular}

Berdasarkan tabel 3 menunjukkan

bahwa dari 60 responden yang memiliki distribusi tertinggi yakni Iklim Kerja yang baik dengan Kinerja Perawat yang baik sebanyak 45 orang $(75,0 \%)$, dan responden yang Iklim Kerja dalam kategori kurang baik dengan Kinerja Perawat yang baik sebanyak 8 orang $(13,3 \%)$, kemudian terdapat sebanyak 5 orang $(8,3 \%)$ yang dalam kategori Iklim Kerja yang kurang baik dengan Kinerja Perawat yang kurang baik, dan distribusi terendah ialah kategori Iklim Kerja yang baik dengan Kinerja Perawat yang kurang baik sebanyak 2 orang $(3,3 \%)$. Berdasarkan hasil analisis data secara statistic dengan menggunakan fisher's exact test, maka di peroleh nilai $p=$ $0.004<\alpha(0.05)$. Maka Ho ditolak, dengan kesimpulan adanya hubungan iklim kerja dengan kinerja perawat kinerja perawat pelaksana di RS Ibnu Sina Makassar.

\section{PEMBAHASAN}

Lingkungan kerja menjadi salah satu factor yang sangat berpengaruh terhadap kepuasan kerja, dimana teori hubungan manusisawi menggunakan faktor kondisi lingkungan kerja sebagai salah satu variabel motivator. Asumsi manajemen yang dipakai adalah orang yang ingin bekerja dalam satu lingkungan aman dan menyenangkan dengan pimpinannya yang adil dan penuh pengertian (Swansburg dan Russel, 2004). Lingkungan kerja atau iklim kerja yang baik mendorong produktivitas perawat untuk melaksanakan dan melengkapi pendokumentasian meskipun dengan beban kerja yang cukup tinggi. Salah faktor tidak terlaksananya pendokumentasian yang baik yaitu beban kerja dan stress kerja yang sering terjadi pada perawat sehingga 7 membuat perawat merasa tidak punya waktu untuk melakukan pendokumentasian

Dalam melakukan pendokumentasian asuhan keperawatan sangat diperlukan motivasi perawat yang timbul dari hati, sehingga perawat perlu menyadari kebutuhan dan kepentingan pendokumentasian asuhan keperawatan (Swansburg dan Russel, 2004). Dalam menciptakan motivasi yang baik, iklim kerja sebaiknya diciptakan dengan cara mengidentifikasi sumber stress seperti berlebihnya jumlah pasien, keadaan dan 
kondisi pasien, kurangnya staf atau tenaga perawatan dan adanya konflik baik diantara perawat maupun dengan tim kesehatan lainnya. Pencegahan yang dilakukan dalam mengurangi stress seperti dalam melakukan perubahan tidak terlalu sering, sering melakukan pelatihan, menciptkana kondisi kerja yang kondusif serta terbuka, komunikasi efektif, mengurangi kontrol yang berlebihan dan memberikan reward dari hasil kerja dan pmeningkatkan kesehjateraan pegawai.

Menurut Robbins \& Judge (2014), bahwa motivasi kerja dan kerja perawat pelaksana di pengaruhi oleh faktor individu perawat yaitu yang pertama latar belakang pendidikan, dimana pada penelitian ini latar belakang pendidikan yang dimiliki oleh perawat sebagian besar Ners (23 orang) yang mana dapat dikatakan bahwa dalam melaksanakan pendokumentasian asuhan keperawatan diperlukan kemampuan intelektual, interpersonal dan teknikal yang memadai sehingga hal ini dapat mempengaruhi kelengkapan dan kualitas dari suatu pendokumentasian, Yang kedua lama kerja dimana dalam penelitian sebagian besar perawat bekerja $\geq 5$ tahun (33 orang) yang menunjukkan bahwa kesetiaan terhadap organisasi masih kuat. Dapat disimpulkan bahwa lama kerja menunjukkan peningkatan pelaksanaan pendokumentasian asuhan keperawatan.
Hasil penelitian Hameed (2011) menunjukkan dari kegagalan dan keberhasilan suatu organisasi bergantung dari kinerja perawat. Olehnya itu, rumah sakit sebaiknya menginvestasikan perawatanya dalam pengembangan karir dengan pelatihan, pendidikan, keterampilan serta sikap perawat. Penelitian Sari dan Rani (2017) mengatakan bahwa kinerja tinggi secara keseluruhan yang dikatakan optimal dapat dilihat dari dimensi kuantitas, kualitas, ketepatan waktu dan sikap kooperatif telah terlaksana.

Penelitian ini juga sesuai dengan teori Swansburg (2004) menjelaskan bahwa iklim kerja yang telah diatur oleh pimpinan atau manajer perawat ditentukan dari perilaku perawat pelaksana untuk menyesuiakan iklim kerja keperawatan tersebut. Hal ini juga sesuai dengan teori Stringer dalam (Hamongan dan Damanik, 2019) dimana dalam suatu organisasi dengan iklim kerja yang kondusif akan berpengaruh pada kinerja perawat sehingga meningkatkan potensi yang dimiliki serta kapasitas produksi.

Hasil Penelitian Asi (2011) mendapatkan bahwa kinerja juga berpengaruh cukup kuat terhadap iklim kerja. Penelitian Hamongan (2019) mengatakan bahwa iklim kerja (struktur, standar, tanggungjawab, pengakuan, tim kerja dan komitmen) ada hubungan dengan kineja perawat. 
Untuk itu semakin baik iklim kerja maka kinerja yang dihasilkan akan baik. Semakin tinggi iklim kerja yang tercipta maka akan semakin tinggi kinerja yang dihasilkan. Hubungan antara iklim kerja dengan kinerja perawat menjelaskan bahwa dengan adanya pengelolaan iklim kerja dari segi struktur, standar, tanggungjawab, pengakuan, dukungan dan komitmen yang baik dan terus di evaluasi di sebuah rumah sakit maka dapat menanamkan persepsi positif pada tiap individu seseorang (perawat pelaksana).

\section{KESIMPULAN}

Kesimpulan dari hasil penelitian ini menunjukkan bahwa terdapat hubungan antara ikli kerja dengan kinerja perawat di RS Ibnu Sina Makassar. Untuk itu diharapkan agar rumah sakit dapat menjaga iklim kerja yang kondusif sehingga mampu mendukung pekerjaan perawat khsusunya dalam melakukan pendokumentasian asuhan keperawatan.

\section{UCAPAN TERIMA KASIH}

Ucapan terima kasih penulis sampaikan kepada Ketua Yayasan Perawat Sul-Sel, Ketua STIKES Panakkukang Makassar, Ketua Prodi Profesi Ners, Dosen STIKES Panakkukang Makkassar, Mahasiswa Prodi S1 Keperawatan Alih Jenjang dan RS Ibnu Sina Makassar.

\section{DAFTAR PUSTAKA}

Asi, P.S. (2011). Pengaruh iklim organisasi dan burnout terhada kinerja perawat RSUD dr. Doris Sylvanus Palangka Raya. Indonesia.

Awases, H.M.,Bezuidenhout M.C., Roos, H.J. (2015). Factors affecting the performance of professional nurses in Namibia. Department of Health Studies, University of South Africa, South Africa.

Hameed, A., \& Waheed, A. (2011). Employee development and its affect on employee performance a conceptual framework. International Journal of Business and Social Sciences.

Hamongan, Damanik .(2019). Hubungan Iklim Organisasi Terhadap Kinerja Perawat Di Rumah Sakit Imelda. Jurnal Ilmiah Keperawatan IMELDA Volume 5 No.1. Diakses 20 Februari 2020,dari http://ojs.stikes-

imelda.ac.id/indekx.php/jilki/article/vie w/330

Minaria.(2019). Hubungan Iklim Organisasi dengan Kinerja Perawat Pelaksana di Rumah Sakit Umum Bunda Thamrin Medan. Diakses 18 Februari 2020 ,

dari http://repositori.usu.ac.id/handle/12345 $\underline{6789 / 16213}$ 
Nursalam (2017). Metodologi Penelitian Ilmu Keperawatan. Jakarta: Salemba Medika

Robbins, S. P., \& Judge, T.A. (2014). Perilaku Organisasi. Jakarta: Salemba Empat

Sari, Rani Puspita.(2017). Pengaruh Iklim Organisasi dan Kepuasan Kerja Terhadap Komitmen Organisasi (Studi Pada Perawat RSIA Eria Bunda Pekanbaru). JOM FISIP Volume 4 No. 2 Diakses 18 Februari 2020, dari http://www.neliti.com/publications/120 938/pengaruh-iklim-organisasi-dankepuasan-kerja-terhadap-komitmenorganisasi-studi

Swansburg, Russel C. (2004). Pengantar Kepemimpinan \& Manajemen Keperawatan untuk Perawat Klinis, Jakarta: EGC. 